\title{
Extracorporeal Membrane Oxygenation in Miliary Tuberculosis and AIDS: A Case Report
}

\author{
Sonia Erika Frick ${ }^{1}$ Christoph Flothmann ${ }^{1}$ Benjamin Preiswerk ${ }^{2}$ Renate Behr ${ }^{3}$ Michele Genoni ${ }^{3}$
}

${ }^{1}$ Internal Medicine, Stadtspital Triemli, Zürich, Switzerland

2 Internal Medicine, Infectious Diseases, Stadtspital Triemli, Zürich, Switzerland

${ }^{3}$ Department of Cardiovascular Surgery, Stadtspital Triemli, Zürich, Switzerland

Thorac Cardiovasc Surg Rep 2015;4:18-20.

\author{
Address for correspondence Sonia Erika Frick, Internal Medicine, \\ Stadtspital Triemli, Birmensdorferstrasse 497, Zuerich 8063, \\ Switzerland (e-mail: sfrick@swissonline.ch).
}

\author{
Abstract \\ Keywords \\ - adult respiratory \\ distress syndrome \\ - human \\ immunodeficiency \\ virus \\ - miliary tuberculosis \\ - extracorporeal \\ membrane \\ oxygenation
}

Background The aim of this study is to present the success of a multidisciplinary approach in a patient with a rare triad of disease.

Case Description A 33-year-old patient with newly diagnosed human immunodeficiency virus infection presented with miliary tuberculosis, consecutive adult respiratory distress syndrome, and multiple-organ failure. An interdisciplinary, time-limited approach combining extracorporeal membrane oxygenation, intensive care therapy, hemodiafiltration, tuberculostatic therapy, steroids, and antiretroviral therapy led to survival despite a low probability at presentation.

Conclusion Even though the use of such extensive and expensive treatment can be questioned, this example encourages an aggressive approach in a young patient, even in situations of multiple diagnosis of individually limited prognosis.

\section{Introduction}

Miliary tuberculosis (TB) with severe adult respiratory distress syndrome (ARDS) and multiple-organ failure (MOF) as a first manifestation of a human immunodeficiency virus (HIV) infection is rare in Western countries. Mortality ranges between 60 and $90 \%$. We report a case of severe ARDS due to miliary TB necessitating extracorporeal membrane oxygenation (ECMO). Despite the limited prognosis due to the severity of the condition plus a newly diagnosed advanced HIV infection, the patient survived.

\section{Case Description}

A 33-year-old woman, native Kenyan, married and living in Switzerland for 7 years, was admitted to an area hospital with fever, diarrhea, vomiting, pain in the right upper abdomen, and weight loss of $5 \mathrm{~kg}$ over 2 weeks. Cholecystitis was suspected (CRP $94 \mathrm{mg} / \mathrm{L}$ [normal < 5], ASAT $96 \mathrm{U} / \mathrm{L}$, ALAT $91 \mathrm{U} / \mathrm{L}$ [normal 32], alkaline phosphatase $332 \mathrm{U} / \mathrm{L}$ [normal
117], lactate dehydrogenase $775 \mathrm{U} / \mathrm{L}$ [normal 214]), and antibiotic therapy with ceftriaxone and metronidazole was started. Radiologic investigations, however, showed major retro- and intraperitoneal lymphadenopathy and hepatomegaly with ascites as well as a suspicion of miliary TB on chest radiography ( - Fig. 1). These findings triggered a HIV test which was positive with $93 \mathrm{CD} 4$ cells $/ \mu \mathrm{L}$ and a viral load of 591,000 copies $/ \mathrm{mL}$. Sputum samples were collected and tuberculostatic therapy with rifampicin, isoniazid, ethambutol, and pyrazinamide was started on day 4 . After an initially stable condition, the respiratory status deteriorated on the 5th hospital day within hours, MOF developed with hemodynamic instability and anuria, necessitating emergent intubation and intensive care therapy. In the following hours, mechanical ventilation became increasingly difficult with a Horowitz index of $70\left(\mathrm{Po}_{2} 9.34 \mathrm{kPa}, \mathrm{Pco}_{2} 7.43 \mathrm{kPa}, \mathrm{SO}_{2}\right.$ $80.3 \%, \mathrm{pH} 7.014, \mathrm{HCO}_{3}-13.5 \mathrm{mmol} / \mathrm{L}$, base eccess -16.1 $\mathrm{mmol} / \mathrm{L}$ ). Therefore, our ECMO team consisting of a surgeon, perfusionist, and anesthesiologist was requested for ECMO support and retrieval of the patient. Due to respiratory failure received

June 29, 2014

accepted

August 5, 2014

published online

November 25, 2014
DOI http://dx.doi.org/

10.1055/s-0034-1394105. ISSN 2194-7635. (c) 2015 Georg Thieme Verlag KG
Stuttgart · New York

License terms

$\Theta(1) \Theta \Theta$ 


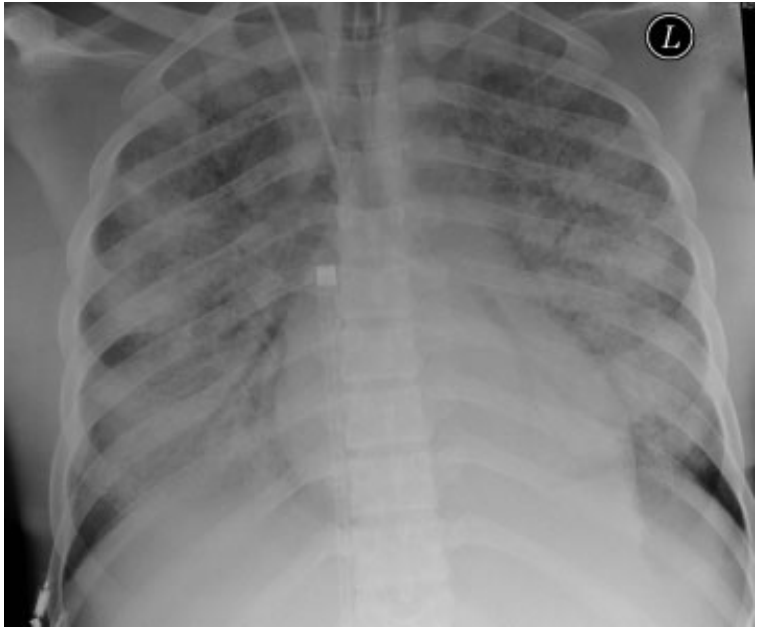

Fig. 1 Chest X-ray at 5:00 AM on the day of admission.

coupled with hemodynamic instability and in view of the pending transport to a tertiary care center, it was decided to put the patient on circulatory-respiratory support (venoarterial ECMO) (-Fig. 2). The ECMO support system, brought by the ECMO team, was primed on scene to guarantee maximal sterility. The left femoral artery (Novaport $17 \mathrm{Fr}$, Novalung, Heilbronn, Germany) and right femoral vein (Edwards $24 \mathrm{Fr}$, Irvine, United States) were cannulated using transcutaneous Seldinger technique and ECMO support (Permanent Life Support Set, Maquet, Hirrlingen, Germany) was commenced with $4 \mathrm{~L} /$ minute pump flow, gas flow $5 \mathrm{~L} / \mathrm{min}$, $\mathrm{FiO}_{2}$ 1.0. In view of the short transport time (40 minutes), distal perfusion of the lower limb of the arterially cannulated left leg was not considered. The patient remained stable during the ensuing transport by ambulance.

In the bronchoalveolar lavage conducted upon arrival in the tertiary care center, mycobacterium tuberculosis could be

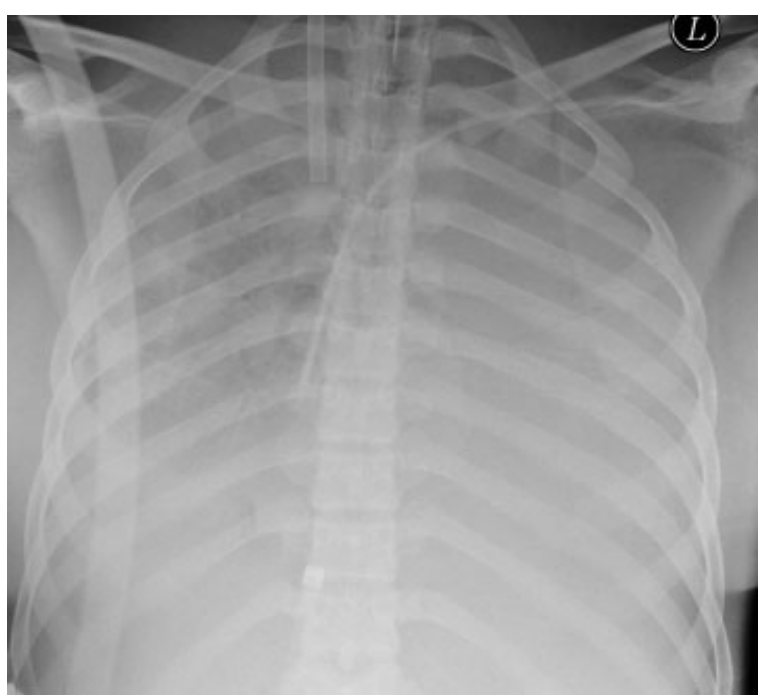

Fig. 2 Chest X-ray at 2:00 PM on the day of admission (intubated; with the extracorporeal membrane oxygenation cannulas in place).

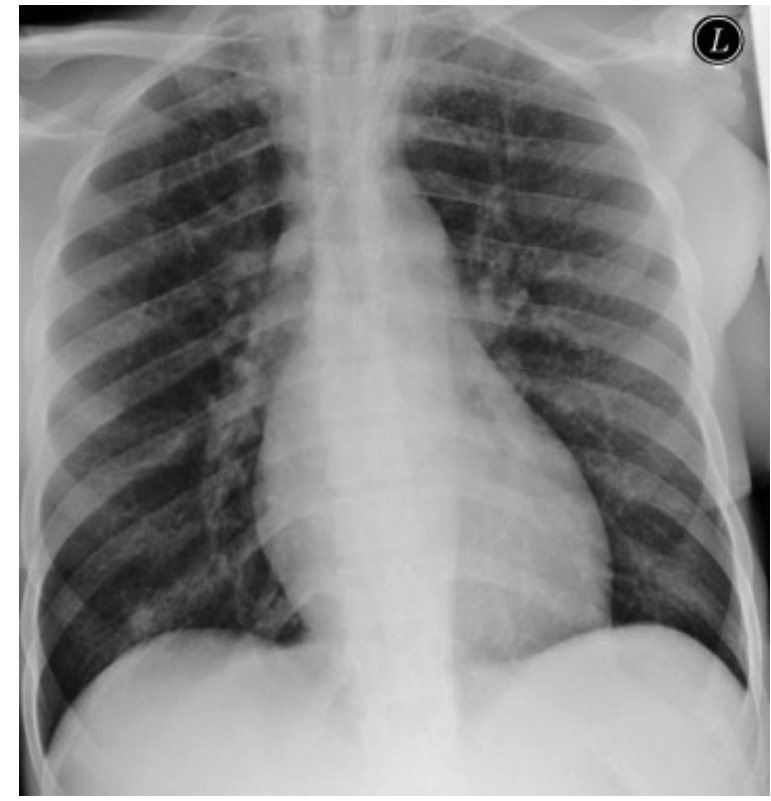

Fig. 3 Chest $\mathrm{X}$-ray 17 days after admission.

visualized on a Ziehl Nielson stain. Testing for pneumocystis jiroveci was negative.

In an interdisciplinary discussion putting the severe condition and the concomitant diagnoses of the patient into perspective, a time-limited trial of full intensive care support for initial 3 days was agreed upon, after which the situation would be reconsidered.

Hemodynamic stabilization could be achieved quickly, thus, shortly after the arrival in the tertiary care center, ECMO-support mode was changed to veno-venous ( $\mathrm{v}-\mathrm{v})$ by cannulation of the right jugular vein (NovaPort 19 Fr, Novalung, Heilbronn, Germany) and removal of the femoral arterial cannula. The subsequent v-v ECMO run was uneventful and the patient could successfully be weaned on day 6 (total ECMO run 147.5 hours, a-v ECMO 4.5 hours, and v-v ECMO 143 hours). Continuous v-v hemodiafiltration was performed for 191 hours, initially connected to the ECMO circuit for the time thereof, and afterward by means of a Shaldon catheter. Mechanical ventilation was necessary for a total of 11 days. Search for other concomitant diseases (lymph node biopsy for possible HIV-associated lymphoma or TB meningitis) was discussed but rejected due to the necessity of anticoagulation on ECMO. Methylprednisolone (125 mg/day) was given for treatment of early ARDS.

The patient recovered slowly. She developed a severe critical illness polyneuropathy which prolonged her intensive care unit stay, but could be transferred to the medical ward on day 15 (-Fig. 3). She also suffered from profound pancytopenia (minimal values: hemoglobin $7.2 \mathrm{~g} / \mathrm{dL}$, thrombocytes $25,000 / \mathrm{mm}^{3}$; leucocytes $4.1 \times 10 / 3$ ), necessitating transfusion of both erythrocytes and thrombocytes, as well as an ongoing hepato- and nephropathy, probably all due to the miliary TB. Antiretroviral treatment (ART) with ritonavirboosted darunavir, lamivudine, and abacavir was started 33 days after admission and initiating TB treatment. The 
patient was referred to a rehabilitation clinic 48 days after hospitalization.

\section{Conclusion}

HIV-positive patients are likely to present with extrapulmonary manifestations of TB, mostly with TB meningitis and/or with disseminated disease. ${ }^{1}$ Miliary TB in HIV-positive patients tends to be more subacute than chronic disease with a tendency to rapid progression. ${ }^{2}$ If the disease is fulminant, patients often present with MOF, ${ }^{3,4}$ septic shock, ${ }^{5}$ and ARDS. ${ }^{6}$ The percentage of miliary TB in HIV-infected patients in one New York City hospital was 38\% compared with $8 \%$ in nonHIV-infected patients. ${ }^{7,8}$ Patients with the lowest CD4 counts appear to have the highest risk for developing disseminated disease. $^{2}$

ARDS in TB develops in approximately 1 to $2 \%$, mortality ranges between 60 and $90 \%{ }^{9,10}$ Older data predict the mortality in patients with TB to be twice as high as in patients with respiratory failure of non-TB origin. ${ }^{11}$

Predictors of development and outcome of ARDS due to TB were found to be elevated liver enzymes, absolute lymphopenia, and a Horowitz index of below 108.5. ${ }^{10}$ In another study, the factors predicting the mortality were reported to be MOF and consolidations on chest X-ray, both probably indicators of the severity of the disease.

ECMO as treatment of TB-induced ARDS is only mentioned in case reports. ${ }^{12}$

Modern ECMO support has lowered the mortality to $40 \%$ in selected patients; however, newly developed mortality prediction scores for patients with respiratory failure on ECMO emphasize the negative impact of immunosuppression on survival. ${ }^{13}$ The etiology of the ARDS being TB in a patient with AIDS puts the estimated mortality close to $100 \%$. In 2005 , Guterman et al published a case report of non-TB pneumonia on ECMO in the context of newly diagnosed HIV infection and discussed this therapy as least controversial. ${ }^{14}$

In the light of these data, an interdisciplinary approach was needed. Our team decided on 72 hours of full supportive therapy and reevaluation thereafter. The improvement in the patient's condition at this time led to a continuation of the therapy, and, eventually, to a good outcome.

To our knowledge, this is the first description of a patient with a newly diagnosed advanced HIV disease, miliary TB, and MOF requiring an ECMO support who survived. Individual tailoring of therapy with a periodic reevaluation of the clinical situation is needed, given the poor initial prognosis, on one hand, and the expected costs, on the other hand. Even though the use of such extensive and expensive treatment can be questioned, this example encourages an aggressive approach in selected patients.

\section{References}

1 Leeds IL, Magee MJ, Kurbatova EV, et al. Site of extrapulmonary tuberculosis is associated with HIV infection. Clin Infect Dis 2012; 55(1):75-81

2 Corbett EL, Charalambous S, Moloi VM, et al. Human immunodeficiency virus and the prevalence of undiagnosed tuberculosis in African gold miners. Am J Respir Crit Care Med 2004;170(6): 673-679

3 Stead WW. Pathogenesis of tuberculosis: clinical and epidemiologic perspective. Rev Infect Dis 1989;11(Suppl 2):S366-S368

4 Sydow M, Schauer A, Crozier TA, Burchardi H. Multiple organ failure in generalized disseminated tuberculosis. Respir Med 1992; 86(6):517-519

5 Ahuja SS, Ahuja SK, Phelps KR, Thelmo W, Hill AR. Hemodynamic confirmation of septic shock in disseminated tuberculosis. Crit Care Med 1992;20(6):901-903

6 Mohan A, Sharma SK, Pande JN. Acute respiratory distress syndrome (ARDS) in miliary tuberculosis: a twelve year experience. Indian J Chest Dis Allied Sci 1996;38(3):157-162

7 Shafer RW, Kim DS, Weiss JP, Quale JM. Extrapulmonary tuberculosis in patients with human immunodeficiency virus infection. Medicine (Baltimore) 1991;70(6):384-397

8 Case records of the Massachusetts General Hospital. Weekly clinicopathological exercises. Case 5-1999. A 37-year-old man with fever and diffuse lymphadenopathy. N Engl J Med 1999; 340(7):545-554

9 Lee PL, Jerng JS, Chang YL, et al. Patient mortality of active pulmonary tuberculosis requiring mechanical ventilation. Eur Respir J 2003;22(1):141-147

10 Sharma SK, Mohan A, Banga A, Saha PK, Guntupalli KK. Predictors of development and outcome in patients with acute respiratory distress syndrome due to tuberculosis. Int J Tuberc Lung Dis 2006; 10(4):429-435

11 Penner C, Roberts D, Kunimoto D, Manfreda J, Long R. Tuberculosis as a primary cause of respiratory failure requiring mechanical ventilation. Am J Respir Crit Care Med 1995;151(3 Pt 1):867-872

12 Petrillo TM, Heard ML, Fortenberry JD, Stockwell JA, Leonard MK Jr Respiratory failure caused by tuberculous pneumonia requiring extracorporeal membrane oxygenation. Perfusion 2001;16(6): 525-529

13 Enger T, Philipp A, Videm V, et al. Prediction of mortality in adult patients with severe acute lung failure receiving veno-venous extracorporeal membrane oxygenation: a prospective observational study. Crit Care 2014;18(2):R67

14 Gutermann H, van Roy B, Meersseman W, Meyns B, Herijgers P. Successful extracorporeal lung assistance for overwhelming pneumonia in a patient with undiagnosed full blown aids-a controversial therapy in HIV-patients. Thorac Cardiovasc Surg 2005; 53(4):252-254 